\title{
The Anti-cancer Drug Chlorambucil as a Substrate for the Human Polymorphic Enzyme Glutathione Transferase P1-1: Kinetic Properties and Crystallographic Characterisation of Allelic Variants
}

\author{
Lorien J. Parker ${ }^{1,2}$, Sarah Ciccone ${ }^{3}$, Louis C. Italiano ${ }^{1,2}$, \\ Alessandra Primavera ${ }^{3}$, Aaron J. Oakley ${ }^{1}$, Craig J. Morton ${ }^{1}$, \\ Nancy C. Hancock ${ }^{1}$, Mario Lo Bello ${ }^{3}$ and Michael W. Parker ${ }^{1,2 \star}$
}

\author{
${ }^{1}$ Biota Structural Biology \\ Laboratory, St. Vincent's \\ Institute of Medical Research, \\ Fitzroy, Victoria 3065, Australia \\ ${ }^{2}$ Department of Biochemistry \\ and Molecular Biology, Bio21 \\ Molecular Science and \\ Biotechnology Institute, The \\ University of Melbourne, 30 \\ Flemington Road, Parkville, \\ Victoria 3010, Australia \\ ${ }^{3}$ Department of Biology, \\ University of Rome "Tor \\ Vergata", Via della Ricerca \\ Scientifica snc 00133 Rome, \\ Italy
}

Received 10 January 2008; received in revised form 14 April 2008; accepted 16 April 2008

Available online

4 May 2008
The commonly used anti-cancer drug chlorambucil is the primary treatment for patients with chronic lymphocytic leukaemia. Chlorambucil has been shown to be detoxified by human glutathione transferase Pi (GST P1-1), an enzyme that is often found over-expressed in cancer tissues. The allelic variants of GST P1-1 are associated with differing susceptibilities to leukaemia and differ markedly in their efficiency in catalysing glutathione (GSH) conjugation reactions. Here, we perform detailed kinetic studies of the allelic variants with the aid of three representative co-substrates. We show that the differing catalytic properties of the variants are highly substrate-dependent. We show also that all variants exhibit the same temperature stability in the range $10{ }^{\circ} \mathrm{C}$ to $45^{\circ} \mathrm{C}$. We have determined the crystal structures of GST P1-1 in complex with chlorambucil and its GSH conjugate for two of these allelic variants that have different residues at positions 104 and 113. Chlorambucil is found to bind in a non-productive mode to the substrate-binding site (H-site) in the absence of GSH. This result suggests that under certain stress conditions where GSH levels are low, GST P1-1 can inactivate the drug by sequestering it from the surrounding medium. However, in the presence of GSH, chlorambucil binds in the H-site in a productive mode and undergoes a conjugation reaction with GSH present in the crystal. The crystal structure of the GSH-chlorambucil complex bound to the ${ }^{*} \mathrm{C}$ variant is identical with the ${ }^{*} \mathrm{~A}$ variant ruling out the hypothesis that primary structure differences between the variants cause structural changes at the active site. Finally, we show that chlorambucil is a very poor inhibitor of the enzyme in contrast to ethacrynic acid, which binds to the enzyme in a similar fashion but can act as both substrate and inhibitor.

(C) 2008 Elsevier Ltd. All rights reserved.

Edited by R. Huber

Keywords: anti-cancer drugs; detoxification; glutathione transferases; polymorphisms; X-ray crystallography

\footnotetext{
${ }^{*}$ Corresponding author. Biota Structural Biology Laboratory, St. Vincent's Institute of Medical Research, Fitzroy, Victoria 3065, Australia. E-mail address: mparker@svi.edu.au.

Present address: A. J. Oakley, Molecular and Health Technologies, Commonwealth Scientific and Industrial Research Organisation, Parkville, Victoria, Australia.

Abbreviations used: *A, I104,A113 GST P1-1 allelic variant and commonly referred to as wild type; *B, V104,A113 GST P1-1 allelic variant; *C, V104,V113 GST P1-1 allelic variant; *D, I104,V113 GST P1-1 allelic variant; CDNB, 1-chloro-2,4dinitrobenzene; NBD-Cl, 7-chloro-4-nitrobenz-2-oxa-1,3-diazole; EA, ethacrynic acid; G-site, glutathione binding site; GSH, glutathione; GST, glutathione S-transferase; GST P1-1, glutathione-S-transferase of Pi Class; H-site, hydrophobic (substrate) binding site; Mes, 2-(N-morpholino)ethanesulfonic acid; MPD, methyl-2,4-pentanediol; rms, root-meansquare; wt, wild type enzyme or *A variant.
} 


\section{Introduction}

Glutathione-S-transferases (GSTs; EC 2.5.1.18) exert their beneficial effect toward toxic and noxious compounds in a variety of ways, e.g. by catalysing different chemical reactions that lead to their detoxification, by binding these compounds or their glutathione (GSH) conjugates, by interacting with different proteins/enzymes involved in certain signalling pathways (e.g. the Jun kinase pathway) or by chemically modifying protein thiol groups with GSH. They are considered to be an important part of a coordinated antioxidant response system., The human cytosolic GSTs are dimeric proteins that can be grouped into at least seven gene-independent classes (Alpha, Mu, Pi, Sigma, Theta, Omega, and Zeta) on the basis of their amino acid sequence. ${ }^{1,2}$ Their three-dimensional folds do not differ significantly despite a low level of sequence homology. Each subunit contains a very similar binding site for GSH (G-site) and a second binding site for the hydrophobic co-substrate (H-site). Structural differences in the H-site confer a certain degree of substrate selectivity. ${ }^{1-3}$

There is much debate about the influence of GST polymorphic enzymes with regards to a patient's susceptibility to cancer, to the modulation of responses to chemotherapy and to an increased risk of developing therapy-related acute myeloid leukaemia in cancer patients thought to be already treated successfully. ${ }^{2}$ GSTs have been implicated strongly in various cancers; for example, in several tumour cell lines there is a remarkable over-expression of these enzymes following exposure to anti-tumour drugs. The acquired resistance that eventually arises in patients, after an initial period of successful treatment, has been related in some cases to the presence of these enzymes. The Pi class GST enzyme, GST P1-1, is believed to be an important factor in such resistance and its over-expression has been reported in a number of different human malignancies including lung, ${ }^{4}$ colon, ${ }^{5,6}$ ovary, ${ }_{12}^{7}$ testis, ${ }^{8}$ bladder, ${ }_{13}^{9}$ mouth, ${ }^{10}$ kidney, $^{11}$ esophagus, ${ }^{12}$ and stomach. ${ }^{13}$ GST P1-1 has been proposed as a possible tumour marker for certain types of cancer (e.g. prostate cancer), where its lack of expression is an unfavourable prognostic factor. ${ }^{14}$
The GST P1-1 enzyme has been the subject of many studies because of its potential role in disease. Our own studies using site-directed mutagenesis and crystallographic analyses have identified residues involved in catalysis and in binding of substrates / inhibitors (e.g. Cys47 and Cys101,15,16 Tyr7, ${ }^{17}$ Tyr49 ${ }^{18}$ and Tyr108 ${ }^{19}$ ) as well as revealing the intrinsic flexibility of certain portions of the molecule (e.g. regions lining the GSH-binding site). ${ }^{20,21}$ The first human Pi isoforms, differing in a single amino acid residue (Ile104 or Val104), were detected in placenta through automated sequencing of the entire polypeptide and led the authors to the suggestion of two independent genes for the enzyme rather than the possibility of allelic isoforms. ${ }^{22}$ Some years later, AlìOsman and co-workers ${ }^{23}$ isolated three human Pi gene variants from normal cells and malignant gliomas and designated them as $\operatorname{HGSTP1}^{*} A$, $H G S T P 1{ }^{*} B$ and $H G S T P 1{ }^{*} C$. A fourth variant, $\operatorname{HGSTP}^{*} D$, has been predicted but so far has not been identified in any human population. These allelic variants differ at either a single codon position (Ile104 (HGSTP1*A), Val104 (HGSTP1*B), Val113 HGSTP1*D) or at two different positions (Val104/ Val113 $\left.\left(\mathrm{HGSTP}^{*} \mathrm{C}\right)\right)$. Since their identification, an increasing number of studies have suggested that these polymorphisms are associated with differing susceptibilities to cancer. ${ }^{24}$

Ethacrynic acid (EA; Fig. 1) has long been identified as a potent inhibitor of GST P1-1 and has been investigated as a potential therapeutic drug for cancer treatment. ${ }^{25}$ Patients receiving treatment with the anti-cancer drug chlorambucil achieved further remission through co-treatment with EA, but side effects including dose-limiting toxicities related to diuresis and therefore subsequent fluid imbalance, hyperglycemia, hypocalcemia and hypomagnesemia proved too severe to continue with Phase II trials. ${ }^{25}$ Efforts are now being made to develop inhibitors with optimised isozyme specificity and fewer side effects. Chlorambucil is a nitrogen mustard alkylating agent (Fig. 1) used as the primary therapy for the treatment of chronic lymphocytic leukaemia, the most common leukaemia in Western countries. $^{26}$ Chlorambucil is believed to elicit its cytotoxicity through the formation of DNA interstrand crosslinks that eventually lead to apoptosis. In<smiles>NC(CCC(=O)NC(CS)C(=O)NCC(=O)O)C(=O)O</smiles>

Glutathione

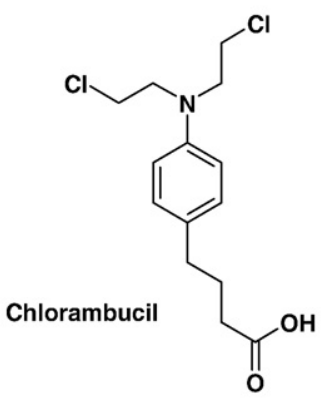<smiles>C=C(CC)C(=O)c1ccc(OCC(=O)O)c(Cl)c1Cl</smiles>

Ethacrynic Acid

Fig. 1. Chemical structures of GSH, chlorambucil and ethacrynic acid. 
chronic lymphocytic leukaemia $60-80 \%$ of patients respond to initial chlorambucil therapy but eventually all patients receiving repeated dosing become resistant to treatment. ${ }^{26}$ Chlorambucil was proposed as a substrate for GST P1-1 through comparative studies of the spontaneous and GST-mediated reaction of chlorambucil with GSH. These studies showed a marked increase in the formation of the conjugated product, monoglutathionyl chlorambucil, in the presence of purified GST P1-1. ${ }^{27}$ A further study reported that the allelic variants of GST P1-1 can differ markedly in their efficiency in catalysing GSH conjugation with chlorambucil, indicating that GST P1-1 polymorphisms could be an important factor in GST-mediated tumour cell resistance to certain anti-tumour drugs. ${ }^{28}$

Here, we report kinetic studies carried out on the allelic variants of GST P1-1 with the aid of three representative co-substrates. ${ }^{19}$ The results show that the presence of Ile or Val at position 104 may alter the catalytic properties in a manner that is highly substrate-dependent. We present crystallographic studies of two GST P1-1 variants, ${ }^{*} \mathrm{~A}$ and ${ }^{*} \mathrm{C}$, which are the most and the least efficient at conjugating chlorambucil, respectively. The results provide direct evidence that chlorambucil can act as a substrate for both variants and thus be detoxified efficiently by this polymorphic enzyme.

\section{Results}

\section{Specific activities and kinetic properties of the GST P1-1 allelic variants with selected substrates}

All the mutant enzymes were expressed in Escherichia coli and easily purified by affinity chromatography in a yield similar to that of wild type ${ }^{*} \mathrm{~A}$ or $w t)$. Their specific activities with three co-substrates (CDNB, EA, NBD-Cl) have been determined and found to be quite similar to those of wild type, with the exception of the I104V ( $\left.{ }^{*} \mathrm{~B}\right)$ mutant, which showed a significant decrease against CDNB, in comparison with wt (Table 1).

Earlier, we reported the kinetic properties of a Tyr108 mutant, an important residue located in the H-site of human GST P1-1, using the above-

Table 1. Specific activities of GSTP1-1 wt and allelic variants (I104V, A113V and I104V/A113V) with selected substrates

\begin{tabular}{lccr}
\hline & \multicolumn{3}{c}{$\begin{array}{c}\text { Substrate specific activity } \\
\left(\mu \mathrm{mol} \mathrm{mg}^{-1} \mathrm{~min}^{-1}\right)\end{array}$} \\
\cline { 2 - 4 } Enzyme & CDNB & EA & NBD-Cl \\
\hline GST P1-1 & $110 \pm 10$ & $1.7 \pm 0.01$ & $3.7 \pm 0.1$ \\
I104V & $60 \pm 8$ & $1.8 \pm 0.03$ & $2.5 \pm 0.08$ \\
A113V & $110 \pm 10$ & $1.4 \pm 0.01$ & $4 \pm 0.12$ \\
I104V/A113V & $70 \pm 6$ & $2.5 \pm 0.04$ & $3 \pm 0.09$ \\
\hline All specific activity values are mean \pm SEM and are based on four \\
replicates.
\end{tabular}

mentioned representative co-substrates. ${ }^{19}$ Because one of the residues occurring in these allelic variants (Ile104) is part of the H-site and is located very close to Tyr108 $(\sim 3 \AA)$, we chose the same substrates for a full kinetic characterisation of these allelic variants and the results are summarised in Table 2. (Kinetic studies with chlorambucil, as co-substrate, have been reported by others. ${ }^{29}$ Unfortunately, the available kinetic assay is not suitable for a detailed kinetic analysis for this substrate and, therefore, we were unable to study this compound any further. (Briefly, the available kinetic assay is an end-point assay which measures the amount of chlorambucil-GSH conjugate formed after incubation of chlorambucil for $30 \mathrm{~min}$ with ${ }^{3} \mathrm{H}$-labelled GSH in the presence of the enzyme. This product is then separated by thinlayer chromatography and further quantified by counting the radioactivity of the product. This method allows a simple kinetic analysis (steadystate kinetic analysis) by using chlorambucil at nonsaturating concentration, but it is not suitable for determination of kinetic constants (e.g. pre-steady state kinetics by stopped-flow), which could give insights in to the catalytic mechanism and explain why the catalytic efficiency of the variants is reduced in comparison with the wild type as reported elsewhere. ${ }^{28}$ ) Among these mutants, the main effect, using CDNB as co-substrate, was observed in the polymorph with the Ile to Val mutation at position 104. There was a significant increase of $K_{\mathrm{m}}{ }^{\mathrm{CDNB}}(2.9 \mathrm{mM})$ and a decrease of about threefold in the catalytic efficiency $\left(18 \pm 2 \mathrm{~s}^{-1}\right.$ $\mathrm{mM}^{-1}$ instead of $\left.66 \pm 3 \mathrm{~s}^{-1} \mathrm{mM}^{-1}\right) . k_{\text {cat }}$ was decreased only slightly and $K_{\mathrm{m}}{ }^{\mathrm{GSH}}$ was completely unaffected. With EA as co-substrate, both the mutants (I104V and A113V) showed similar effects: $K_{\mathrm{m}}{ }^{\mathrm{EA}}$ and $k_{\text {cat }}$ were significantly lower than those of the wt enzyme and, as a result, the catalytic efficiency did not change. Finally, with NBD-Cl as co-substrate, the main effect was a fourfold decrease of $k_{\text {cat }}$ while both $K_{\mathrm{m}}{ }^{\mathrm{GSH}}$ and $K_{\mathrm{m}}{ }^{\mathrm{NBD}-\mathrm{Cl}}$ were affected only slightly.

\section{Thermal stability and inhibition studies of the GST P1-1 allelic variants}

Thermal stability of GST P1-1 wt and its allelic variants (I104V, A113V and I104V / A113V) was also studied at different temperatures $\left(10-55{ }^{\circ} \mathrm{C}\right)$ for $15 \mathrm{~min}$. As shown in Fig. 2, there was no significant decrease in the activity upon temperature increase up to $45^{\circ} \mathrm{C}$, for any of the enzymes tested. At this last value, we prolonged the incubation time up to $1 \mathrm{~h}$ (no change) and assayed again the activity after $24 \mathrm{~h}$ incubation with no remarkable change in the activity (data not shown). However, at higher temperatures a different heat inactivation between wt and the $1104 \mathrm{~V}$ mutant enzyme was observed (Fig. 2). In fact, upon incubation at $50{ }^{\circ} \mathrm{C}$ for $15 \mathrm{~min}$, this mutant showed a residual activity of $55.8 \%$ in comparison with the value of $65.3 \%$ for the wt enzyme. This effect was not observed in the other single-mutant (A113V) enzyme that behaved like the wt enzyme, whilst the double mutant I104V/ 
Table 2. Steady-state kinetic parameters of wt, I104V, A113V, I104V/A113V towards selected substrates

\begin{tabular}{|c|c|c|c|c|c|}
\hline Substrate & Enzyme & $K_{\mathrm{m}}^{\mathrm{GSH}}(\mathrm{mM})$ & $K_{\mathrm{m}}^{\operatorname{cosub}}(\mathrm{mM})$ & $k_{\text {cat }}\left(\mathrm{s}^{-1}\right)$ & $k_{\text {cat }} / K_{\mathrm{m}}^{\operatorname{cosub}}\left(\mathrm{s}^{-1} \mathrm{mM}^{-1}\right)$ \\
\hline \multirow[t]{4}{*}{ CDNB } & GST P1-1 & $0.15 \pm 0.03$ & $1.2 \pm 0.1$ & $79 \pm 3$ & $66 \pm 3$ \\
\hline & I104V & $0.11 \pm 0.03$ & $2.9 \pm 0.4$ & $52 \pm 2$ & $18 \pm 2$ \\
\hline & A113V & $0.13 \pm 0.002$ & $1.4 \pm 0.09$ & $79 \pm 2$ & $56 \pm 2$ \\
\hline & I104V/A113V & $0.08 \pm 0.01$ & $2.3 \pm 0.09$ & $48 \pm 3$ & $21 \pm 3$ \\
\hline \multirow[t]{4}{*}{ EA } & GST P1-1 & $0.17 \pm 0.05$ & $0.21 \pm 0.02$ & $3.2 \pm 0.2$ & $15 \pm 2$ \\
\hline & I104V & $0.17 \pm 0.02$ & $0.08 \pm 0.003$ & $1.8 \pm 0.3$ & $22.5 \pm 3$ \\
\hline & A113V & $0.21 \pm 0.04$ & $0.09 \pm 0.009$ & $1.3 \pm 0.5$ & $14 \pm 2$ \\
\hline & I104V/A113V & $0.20 \pm 0.01$ & $0.06 \pm 0.01$ & $2.3 \pm 0.6$ & $38 \pm 2$ \\
\hline \multirow[t]{4}{*}{$\mathrm{NBD}-\mathrm{Cl}$} & GST P1-1 & $0.008 \pm 0.002$ & $0.004 \pm 0.001$ & $1.0 \pm 0.2$ & $250 \pm 12$ \\
\hline & I104V & $0.007 \pm 0.001$ & $0.007 \pm 0.003$ & $0.26 \pm 0.08$ & $37 \pm 5$ \\
\hline & A113V & $0.014 \pm 0.008$ & $0.011 \pm 0.009$ & $1.3 \pm 0.09$ & $118 \pm 7$ \\
\hline & I104V / A113V & $0.003 \pm 0.0004$ & $0.002 \pm 0.0002$ & $0.52 \pm 0.05$ & $260 \pm 10$ \\
\hline
\end{tabular}

Values \pm SEM were estimated by non-linear regression analysis of experimental data using Graph Pad Prism 4.0 software.

A113V showed, at $50{ }^{\circ} \mathrm{C}$, a value of residual activity in between those of the two single mutants (Fig. 2). The different behaviour of the I104V mutant in comparison with the A113V can be explained readily by the location of Ile104 in helix 4, an important and somewhat flexible region involved in catalysis. ${ }^{21}$ In contrast Ala113 is located far from the active site and therefore its mutation does not affect the stability of the enzyme, at $50{ }^{\circ} \mathrm{C}$, in comparison with wt enzyme.

It has been reported that chlorambucil can be conjugated to GSH in the presence of human GST P1-1 and its allelic variants. ${ }^{28}$ We examined whether this anti-tumour drug could act as inhibitor by determining the $\mathrm{IC}_{50}$ for the GST activity, as assayed with CDNB as co-substrate. The results shown in Fig. 3 indicate that chlorambucil is a very poor inhibitor of GST P1-1 with no difference between wt and the mutant enzymes.

\section{Structure of chlorambucil GST P1-1 complex}

We obtained the structure of chlorambucil bound to GST P1-1 from enzyme that had been co-crystallised with the drug (see Table 3). Chlorambucil binds in the H-site with its aromatic ring stacked between the aromatic side chains of Phe 8 and Tyr108 (Fig.

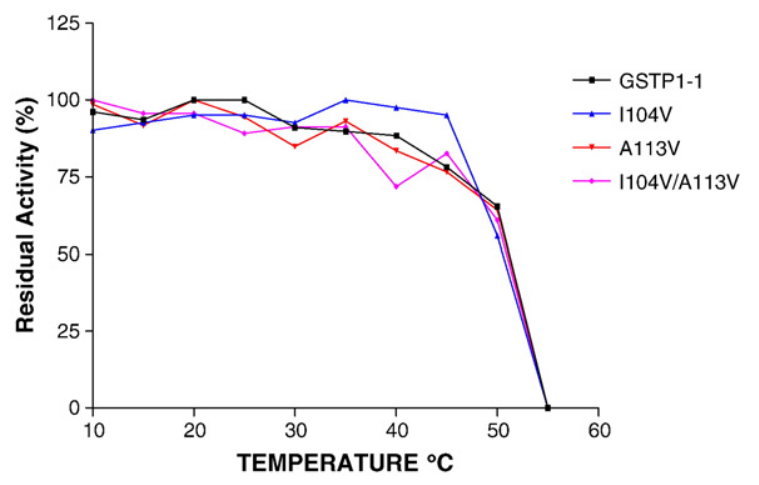

Fig. 2. Thermal stability of GSTP1-1 wt and its allelic variants (I104V, A113V and $\mathrm{I} 104 \mathrm{~V} / \mathrm{A} 113 \mathrm{~V}$ ) at different temperatures $\left(10-55^{\circ} \mathrm{C}\right)$. 4a). The electron density for chlorambucil is good except for the carboxyl tail, which points out of the $\mathrm{H}$-site into solvent and is presumably fairly mobile. In total, there are 22 van der Waals interactions $(<4 \AA)$ but no potential hydrogen bonding interactions between protein and drug (Fig. 4c). Superposition of the chlorambucil complex onto the GSH complex structure (determined in the same space group; PDB ID 5GSS) ${ }^{30}$ indicates no significant movement of side chains in the active site. The rootmean-square (rms) deviation in alpha carbon positions is $0.2 \AA$ with no deviation greater than $0.5 \AA$. The chlorambucil molecule is positioned in the active site so that GSH could still fit into the G-site without steric clashes with the drug. However, the reactive chloroethyl groups point away from the G-site and hence chlorambucil has bound in a nonproductive mode with respect to possible conjugation with GSH.

It has been reported that chlorambucil binds to GST P1-1 so that one of the alkylating arms of the drug binds to Cys47 of one subunit and the other arm to Cys101 of the second subunit. ${ }^{31}$ However, Cys47 and Cys101 residues are approximately $20 \AA$ apart in the crystal structure of the enzyme. Modelling suggests a crosslink is possible assuming a conformational change in the apo enzyme that

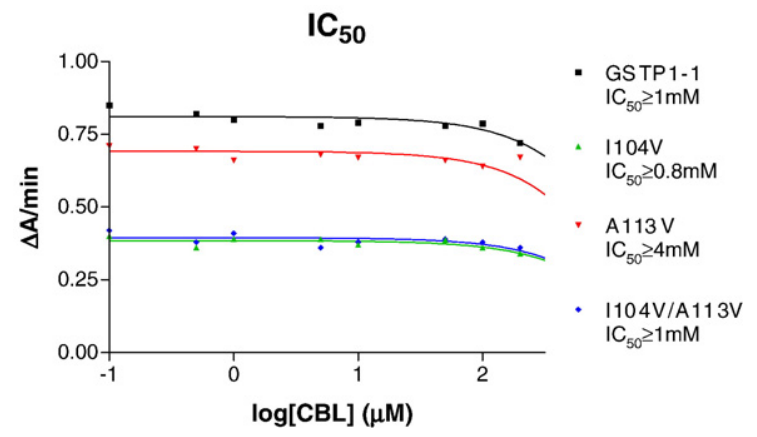

Fig. 3. Activity measurements of the allelic variants. The $\mathrm{IC}_{50}$ values were determined by assaying the activity at $340 \mathrm{~nm}, 25^{\circ} \mathrm{C}$, in the presence of $1 \mathrm{mM} \mathrm{GSH}, 1 \mathrm{mM}$ CDNB and various concentrations of chlorambucil (0.1$500 \mu \mathrm{M})$. 
Table 3. Summary of data collection and structure refinement

\begin{tabular}{|c|c|c|c|}
\hline & Chlorambucil & Chlorambucil-GSH & Chlorambucil-GSH \\
\hline \multicolumn{4}{|l|}{ A. Data collection } \\
\hline Polymorphic variant & $*^{*} \mathrm{~A}$ & *A & ${ }^{*} \mathrm{C}$ \\
\hline Temperature (K) & 100 & 100 & 100 \\
\hline Space group & C2 & $C 2$ & $P 2_{1}$ \\
\hline \multicolumn{4}{|l|}{ Cell dimensions } \\
\hline$a(\AA)$ & 77.8 & 77.4 & 68.8 \\
\hline$b(\AA)$ & 89.9 & 89.4 & 89.2 \\
\hline$c(\AA)$ & 69.1 & 69.0 & 74.5 \\
\hline$\beta\left({ }^{\circ}\right)$ & 97.7 & 98.0 & 97.0 \\
\hline GST monomers in asymmetric unit & 2 & 2 & 4 \\
\hline Maximum resolution $(\AA)$ & 1.90 & 1.55 & 1.90 \\
\hline No. crystals & 1 & 1 & 1 \\
\hline No. observations & 79,458 & 476,536 & 287,056 \\
\hline No. unique reflections & 33,344 & 65,481 & 68,723 \\
\hline Data completeness (\%) & $89.9(87.9)^{\mathrm{a}}$ & $98.6(92.7)$ & $97.7(96.0)$ \\
\hline$R_{\text {merge }}$ & $8.5(26.2)$ & $6.2(21.4)$ & $11.2(63.8)$ \\
\hline$I / \sigma$ & $19.0(3.9)$ & $22.5(5.7)$ & $13.0(2.0)$ \\
\hline Multiplicity & 2.4 & 7.2 & 4.2 \\
\hline \multicolumn{4}{|l|}{ B. Refinement } \\
\hline \multicolumn{4}{|l|}{ Non-hydrogen atoms } \\
\hline Protein & 3276 & 3300 & 6607 \\
\hline Chlorambucil & 19 & - & - \\
\hline Chlorambucil-GSH & - & 76 & 152 \\
\hline GSH (unconjugated) & _- & 40 & 80 \\
\hline Mes & 24 & 24 & 36 \\
\hline $\mathrm{SO}_{4}$ & - & 5 & 5 \\
\hline $\mathrm{CO}_{3}$ & - & - & 4 \\
\hline $\mathrm{Ca}^{2+}$ & - & 1 & 4 \\
\hline $\mathrm{Cl}^{-}$ & 1 & 2 & 4 \\
\hline Solvent $\left(\mathrm{H}_{2} \mathrm{O}\right)$ & 331 & 627 & 905 \\
\hline Resolution $(\AA)$ & 1.90 & 1.55 & 1.90 \\
\hline$R_{\text {cryst }}^{c}(\%)$ & 17.6 & 17.0 & 16.6 \\
\hline$R_{\text {free }}(\%)$ & 23.3 & 20.0 & 22.2 \\
\hline \multicolumn{4}{|l|}{ Reflections used in $R_{\text {conv }}$ calculations: } \\
\hline Number & 31,690 & 62,188 & 65,248 \\
\hline Completeness (\%) & 84.9 & 97.8 & 97.7 \\
\hline \multicolumn{4}{|l|}{ rmsd from ideal geometry } \\
\hline Bond lengths $(\AA)$ & 0.016 & 0.013 & 0.016 \\
\hline Bond angles $\left({ }^{\circ}\right)$ & 1.5 & 1.6 & 1.5 \\
\hline Wilson $B$-factor $\left(\AA^{2}\right)$ & 17.2 & 14.3 & 19.7 \\
\hline \multicolumn{4}{|l|}{ Mean $B$ (protein) $\left(\AA^{2}\right)$} \\
\hline Main chain & 17.1 & 13.6 & 16.5 \\
\hline Side chain & 18.4 & 14.8 & 17.4 \\
\hline \multicolumn{4}{|l|}{ Mean $B$} \\
\hline Solvent $\left(\AA^{2}\right)$ & 25.0 & 27.2 & 26.3 \\
\hline Chlorambucil $\left(\AA^{2}\right)$ & 32.1 & - & - \\
\hline Chlorambucil-GSH $\left(\AA^{2}\right)$ & - & 22.7 & 25.0 \\
\hline \multicolumn{4}{|l|}{ Residues in the Ramachandran plot } \\
\hline In most favoured regions (\%) & 92.2 & 93.3 & 93.0 \\
\hline In disallowed regions $(\%)$ & 0 & 0 & 0 \\
\hline
\end{tabular}

would cause burial of the G-site. This is consistent with the observation that crosslinking occurs only in the absence of GSH, a scenario not likely to occur in normal unstressed cells. The failure to observe the crosslinked complex here may be due to the presence of the reductant, DTT, an essential ingredient of the crystallisation conditions. Thus, under stressed conditions, where GSH levels are depleted, the enzyme itself may serve as a trapping agent by the non-productive binding mode seen here and/or by crosslinking the enzyme, resulting in a decrease of available chlorambucil for DNA modification.

\section{Structure of chlorambucil-GSH GST P1-1 complex}

Chlorambucil was introduced into preformed crystals of the enzyme bound to GSH. The crystallographic results show that the enzyme was able to catalyse the conjugation reaction between drug and GSH so that the product is observed in the active site 
(a)
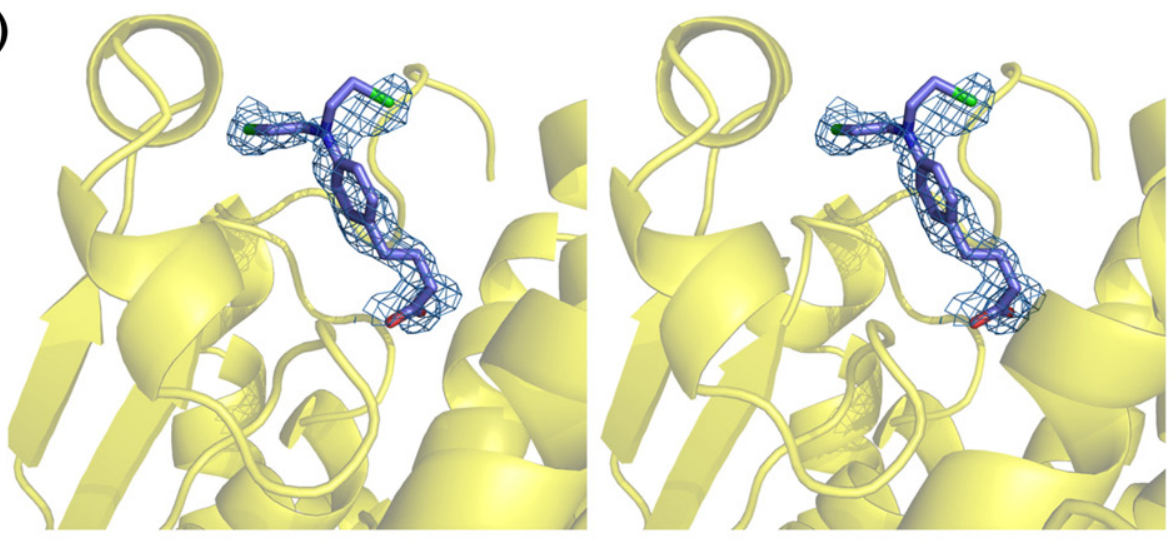

(b)
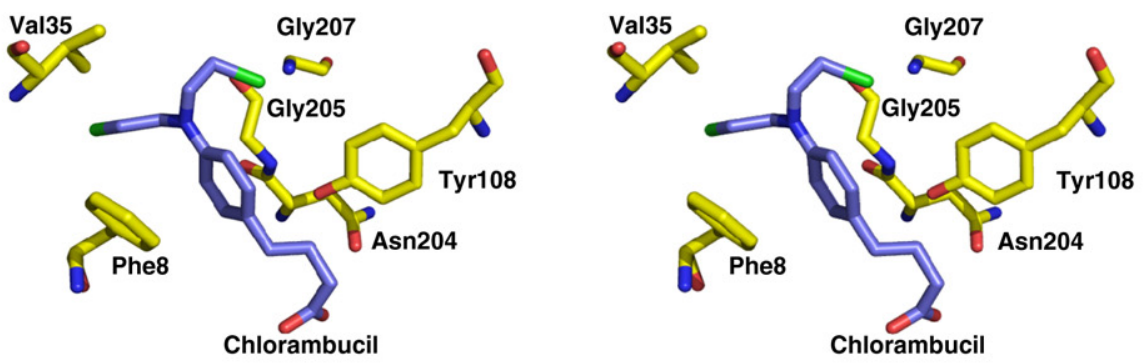

(c)

(d)
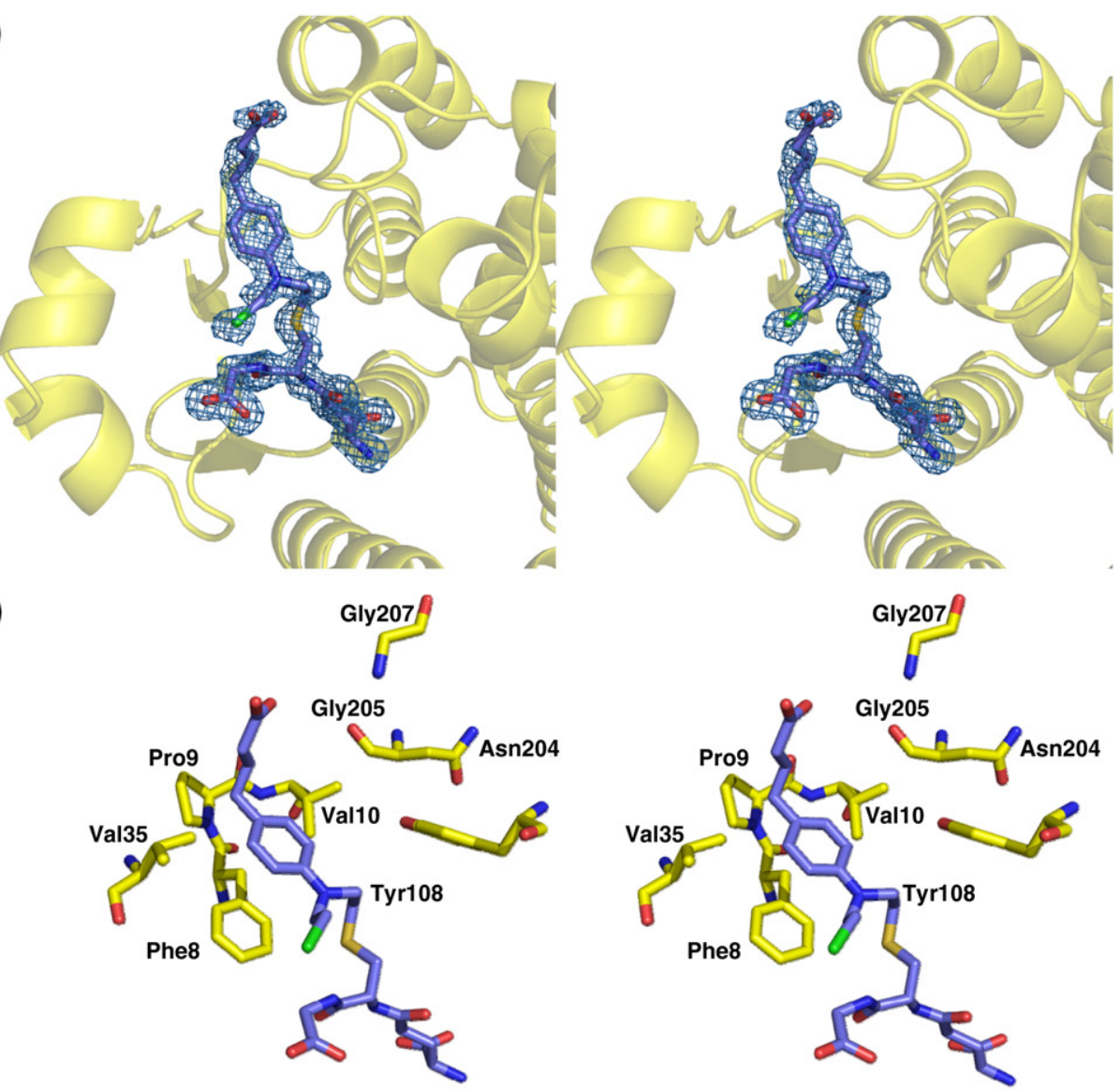

Chlorambucil-glutathione Conjugate

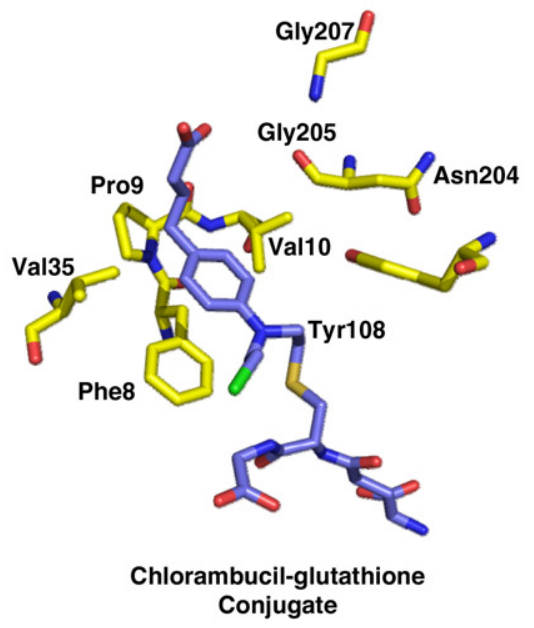

Fig. 4. Binding of chlorambucil to human GST P1-1. (a and b) Stereo diagrams of the chlorambucil complex in the vicinity of the H-site. (c and d) Stereo diagrams of the chlorambucil-GSH complex in the vicinity of the H-site of human *A GST P1-1. The $2 F_{\mathrm{o}}-F_{\mathrm{c}}$ electron density maps are calculated from the final model and contoured at the $0.8 \sigma$ level in the vicinity of the ligand. 
with chlorambucil sitting in the H-site and GSH in the G-site (Fig. 4b). The GSH moiety is located in an almost identical position to that reported for the structure of the GSH complex (PDB ID 5GSS) ${ }^{30}$ except for a rotation of the thiol moiety that displaces one of the chloro groups of chlorambucil. The GSH moiety makes the usual interactions with the side chains of Trp38, Gln51, Asp98, Gln64, Ser65, mainchain interactions with Leu52 and Ser65, a van der Waals interaction with Arg13 as well as a number of water-mediated interactions. The aromatic ring of the chlorambucil moiety forms a pi-pi stacking interaction with Phe8 and is involved in van der Waals interactions with Val35, Val10, Pro9 and Gly205 (Fig. $4 \mathrm{~d})$. The carboxylate moiety of chlorambucil makes water-mediated interactions with the hydroxyl of Asn204 and the amino group of Gly207. The remaining chloroethyl group appears to be relatively flexible and does not form any contact with the protein, in either subunit. The occupancy of the conjugate refines to about $80 \%$, with the remainder being unbound GSH in the active site. The unconjugated GSH lies in virtually the same position as that of the conjugate, except that the thiol of GSH is rotated so it points towards the hydroxyl of Tyr7.

A comparison of the chlorambucil-GSH with previously published GSH complex structures (PDB ID 5 GSS $)^{30}$ reveals small but significant movements of side chains in the active site (Fig. 5a). Phe8 has shifted approximately $0.4 \AA$ toward the chlorambucil moiety to enhance the pi-pi interaction. A loop region comprising residues 205 to 207 has also shifted away from the $\mathrm{H}$-site, by approximately $0.5 \AA$, to accommodate the chlorambucil molecule. There has also been a conformational change in Val35 of both subunits, whereby the CG2 atom now points towards the H-site, instead of away, and is now involved in hydrophobic interactions with the conjugate.

It has been reported that chlorambucil does not form a complex with GST P1-1 in the presence of $\mathrm{GSH}^{31}$ although other work has shown that chlorambucil is a substrate for the enzyme. ${ }^{27}$ The results presented here show directly that chlorambucil does react with GSH in the presence of the enzyme to form a drug-conjugate enzyme complex.

\section{Structure of the chlorambucil-GSH ${ }^{*} \mathrm{C}$ variant GST P1-1 complex}

Chlorambucil was introduced into preformed crystals of the ${ }^{*} \mathrm{C}$ (Val104, Val113) variant enzyme bound to GSH. Despite the lower catalytic efficiency of the ${ }^{*} \mathrm{C}$ variant for chlorambucil, ${ }^{28}$ the enzyme was still capable of conjugating the drug to GSH in the crystal. The crystal structure of the complex is identical with the same complex of wt (rms deviation in alpha-carbon atoms being less than $0.4 \AA$ ) with no significant difference in water structure or temperature factors between the respective active sites or across the dimer interfaces. The crystal structure of the ${ }^{*} \mathrm{C}$ variant in complex with GSH is also identical with the other variant complexes (unpublished results).

\section{Discussion}

The purification yield was similar for all the enzymes (wt, I104V, A113V and I104V/A113V), consistent with their similar affinity for GSH. In fact, the kinetic studies carried out on the wt and mutant enzymes suggested that the G-site (the binding site for GSH) was essentially unaffected, as indicated by the very similar values of $K_{\mathrm{m}}{ }^{\mathrm{GSH}}$ (Table 2). Due to the direct crystallographic evidence of chlorambucil being a true co-substrate in this study, we were prompted to consider a full kinetic study with this compound. Unfortunately, the available assay is not suitable for this type of study (see Results). ${ }^{29}$

The crystal structures of GST P1-1 in complex with S-hexyl GSH ${ }^{32}$ or with $\mathrm{EA}^{33}$ suggested that the Ile104 residue is located in the H-site close $(\sim 3 \AA)$ to Tyr108, whilst the Ala113 residue is located at the N-terminal end of helix 5 and completely outside the active site $(\sim 18 \AA)$. Most changes in the kinetic parameters of the Ile104 variant with respect to the wt enzyme (Table 2) can be explained by the crystal structures and will be discussed below. Changes observed in the A113V mutant with EA as cosubstrate (e.g. a significant decrease of $k_{\text {cat }}$ and $K_{\mathrm{m}}$ EA values), are more difficult to explain because of the large distance between the position of this residue and the active site. Previous studies have suggested that the Ile to Val mutation at position 104 may alter the overall geometry of the $\mathrm{H}$-site or that this residue may influence, through a "second sphere effect", the important role of Tyr108. ${ }^{34}$ Studies of the catalytic mechanism of human GST P1-1 and the role of Tyr108 may help to explain the kinetic properties of all these allelic variants. As reported previously, ${ }^{19,35}$ the effect of the mutations may vary according to the type of catalytic mechanism and substrate used by the same enzyme. For example, CDNB is a classical substrate of a conjugation reaction with GSH, and it has been demonstrated that the rate-limiting step of this reaction is of a physical nature, ${ }^{20}$ and that Tyr108 has no effect on its catalytic mechanism. ${ }^{19}$ In the case of the I104V mutant, $k_{\text {cat }}$ was almost unaffected whilst $K_{\mathrm{m}}{ }^{\mathrm{CDNB}}$ was increased, suggesting that the mutation (Ile to Val) may affect the binding of CDNB because of a different hydrophobicity or bulkiness of the changed residue.

In the case of ethacrynic acid as co-substrate, Tyr108 has a catalytic role in the Michael addition reaction by stabilising the transition state with its hydroxyl group. Thus, any change in residues located close to Tyr108 may also affect catalysis. Indeed, $k_{\text {cat }}$ of the I104V mutant was decreased significantly (about twofold), consistent with the above suggestion. The additional threefold decrease of $K_{\mathrm{m}}{ }^{\mathrm{EA}}$ appears to be specific for this mutation and seems to favour the binding of EA with respect to wt.

Finally, with NBD-Cl as co-substrate, the most dramatic change in the I104V mutant was a fivefold decrease of $k_{\text {cat }}$ with a concomitant reduction of its catalytic efficiency (from $250 \pm 12 \mathrm{~s}^{-1} \mathrm{mM}$ to $37 \pm$ $5 \mathrm{~s}^{-1} \mathrm{mM}$ ). It has been reported that with NBD-Cl the rate-limiting step seems to be related to slow 
motions of helix 4 (the "physical" step), ${ }^{21}$ where both Tyr108 and Ile104 are located. The rigidity of helix 4 was explained by the presence of a possible hydrogen bond between the hydroxyl group of Tyr108 and the oxygen atom of NBD-Cl, and the lack of this hydrogen bond in the $\mathrm{Y} 108 \mathrm{~F}$ mutant increased $k_{\text {cat }}$ about eightfold. ${ }^{19}$ In the I104V mutant, the substitution of Ile for Val appears to affect $k_{\text {cat, }}$ possibly by reinforcing this link between the substrate and helix 4 . In conclusion, among the allelic variants, the most important changes in the kinetic properties occur at position 104, suggesting that this residue may have an ancillary role in catalysis or in binding of the substrates with respect to the catalytically important Tyr108 residue.

Previous studies on the thermal stability of the I104V mutant ${ }^{34}$ or on the allelic variants ${ }^{23}$ reported that the I104V mutant (corresponding to the allelic variant $H G S T P 1^{*} B$ ) was less thermostable at $45^{\circ} \mathrm{C}$ than the wt (the allelic variant $\operatorname{HGSTP} 1^{*} A$ ), and that this stability ratio can be reversed upon addition of
GSH. Our studies carried out at the same temperature $\left(45^{\circ} \mathrm{C}\right)$ did not support these findings. We have incubated all the enzymes for $1 \mathrm{~h}$ at $45^{\circ} \mathrm{C}$ and observed no inactivation of enzymatic activity. Even after incubation for $24 \mathrm{~h}$, the activity of all the samples was unaffected. Only after a short incubation at $50{ }^{\circ} \mathrm{C}$ did we find that the $1104 \mathrm{~V}$ mutant is less thermostable than the wt, consistent with results published earlier. ${ }^{35}$ On the basis of these last results, it is questionable whether the thermostability of the allelic variants (namely, that of I104V mutant) can be considered to be a relevant factor in explaining their different susceptibility to tumour formation, as shown by these GST P1-1 allelic variants in several epidemiological studies.

Our crystallographic results show that chlorambucil binds in the H-site of GST P1-1. Although the chloroethyl arms of the chlorambucil and chlorambucil-GSH conjugate molecules point in opposite directions when bound to the enzyme, the aromatic rings lie in the same plane (Fig. 5b). The drug sits slightly
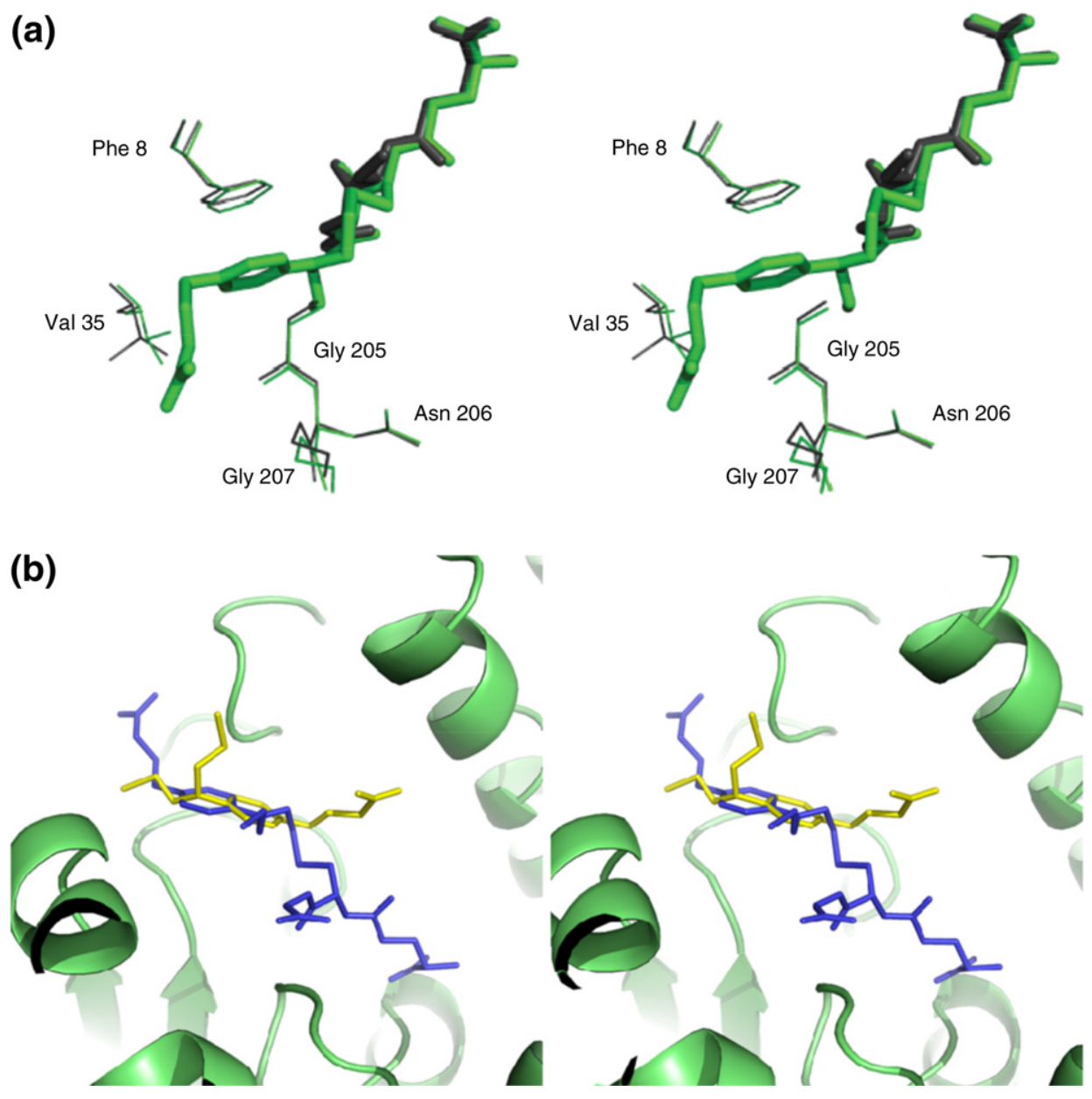

Fig. 5. Superposition of structures. (a) GSH bound to GST is in grey (5GSS) and chlorambucil-GSH conjugate bound to GST is in green. Surrounding residues are depicted as sticks to highlight the movement of the side chains in response to ligand binding. (b) Chlorambucil-GSH conjugate is in blue and chlorambucil is in yellow. (c) EA bound in a nonproductive mode is in red and chlorambucil bound in a non-productive mode is in yellow. (d) EA-GSH bound in the IN mode is in orange, EA-GSH bound in the OUT mode is in pink and chlorambucil-GSH bound in the OUT mode is in blue. 


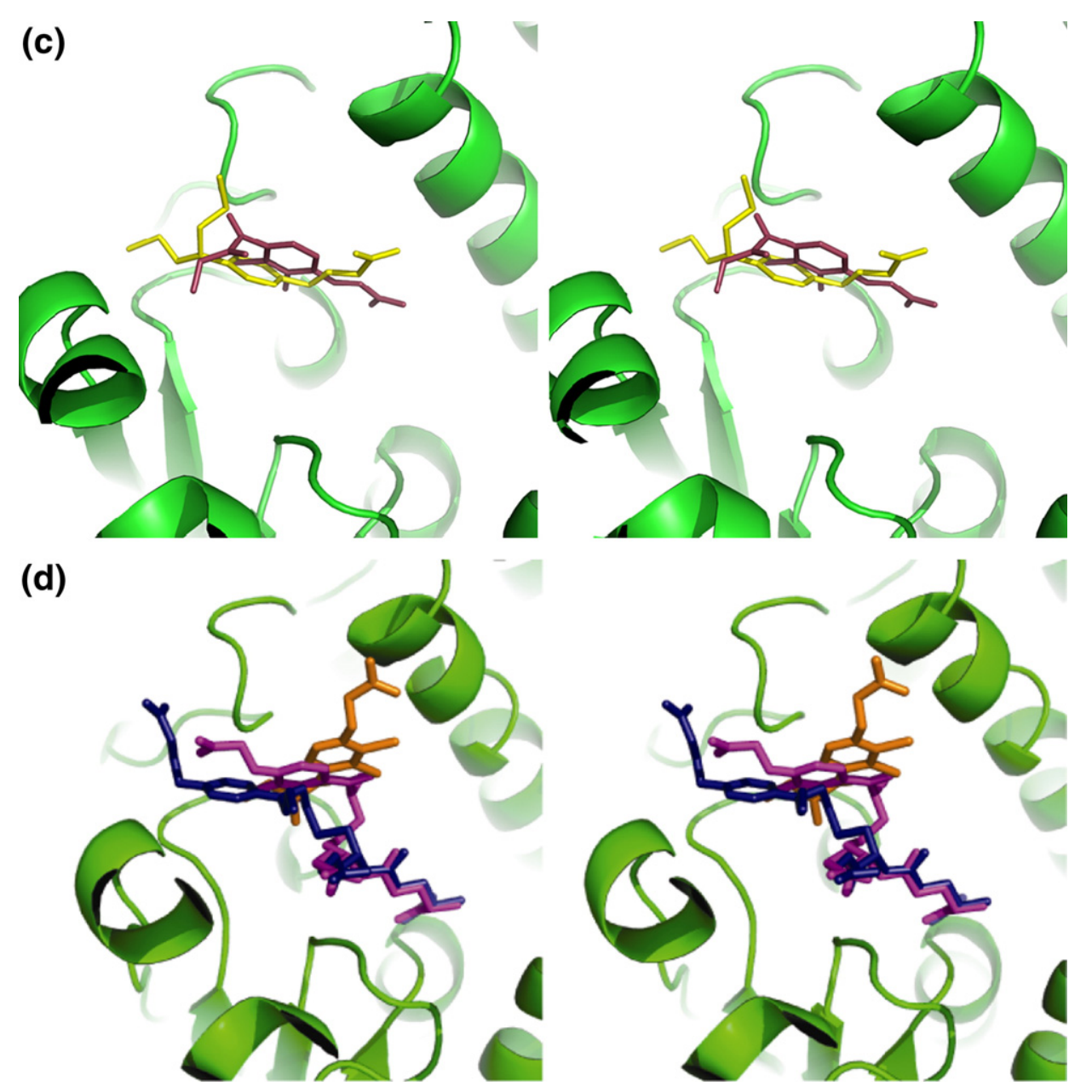

Fig. 5 (legend on previous page)

further into the G-site in the chlorambucil complex, presumably due to the absence of GSH from that site.

The binding of chlorambucil in the chlorambucilGST P1-1 complex is reminiscent of the nonproductive binding mode observed for EA to the same enzyme in the absence of GSH. ${ }^{33}$ In both cases the aromatic ring of the drugs stack between the aromatic side chains of Phe 8 and Tyr108 and their flexible carboxylic tails point into the active site (Fig. 5c). The aromatic rings of the drugs lie in a fairly similar position, albeit in different planes, resulting in an optimisation of pi stacking with Tyr108 for the EA molecule and an optimised pi stack with Phe8 for the chlorambucil molecule. There is no significant movement of side chains within the vicinity of either drug: the rms deviation of alpha-carbon atoms being $0.1 \AA$. EA-GSH can bind in two different modes to GST P1-1: in the IN mode the aromatic ring of EA stacks primarily against the side chain of Tyr108 whereas in the OUT mode the EA ring stacks between both Phe8 and Tyr108 (Fig. 6d). ${ }^{33,36}$ We found that chlorambucil exclusively adopts the OUT mode of binding in the chlorambucil-GSH complex (Fig. 5d). Again, there is no significant movement of side chains within the vicinity of either drug with the rms deviation in alpha-carbon atoms being $0.2 \AA$.
Residue 104 is within van der Waals contact distance (3.3 $\AA$ ) of chlorambucil (Fig. 4) and hence is in a position to influence drug binding and conjugation with GSH. All human GST P1-1 crystal structures determined to date have used the ${ }^{*} A$ variant (wt), with only a couple of exceptions: the ${ }^{*} \mathrm{~B}$ variant structure in complex with S-hexylGSH and (9R,10R)-9-(S-glutathionyl)-10-hydroxy-9,10-dihydrophenanthrene has been determined, ${ }^{37}$ and the crystal structures of both ${ }^{*} \mathrm{~A}$ (I104,A113) and ${ }^{*} \mathrm{~B}$ (V104,A113) variants in complex with (+)-anti-7,8dihydroxy-9,10-oxy-7,8,9,10-tetrahydrobenzo[ $a]$ pyrene have been determined more recently. ${ }^{38}$ Those studies revealed that residue 104 dictated the binding mode of the ligand, possibly due to reorganisation of a network of water molecules in its vicinity and to restricted conformational freedom of the isoleucine variant at position 104 compared to valine, which could adopt two distinct conformations. In contrast, we see no consistent difference in the way chlorambucil binds to the active site or in the active site water structure between wt and ${ }^{*} \mathrm{C}(\mathrm{V} 104, \mathrm{~V} 113)$ variants. These results suggest that residue 104 dictates the binding mode only in the case of certain other bulky ligands.

Residue 113 is more than $18 \AA$ from the bound chlorambucil and hence it is difficult to understand 
how it influences enzymatic activity. $\mathrm{Hu}$ and coworkers have postulated that residue 113, located at the top of the helix-turn-helix motif between helices 4 and 5, and positioned at the opening of a solvent channel in the dimer interface, forms a "hydrophobic clamp" with its symmetry-related mate from the other subunit. ${ }^{39}$ The clamp possibly controls access to substrates and, therefore, the hydrophobicity and the size of residue 113 could be important in codetermining the substrate specificity of the enzymes. However, the location of chlorambucil bound in the crystal structures of the variant GSH chlorambucil complexes provides no evidence to support this hypothesis. The active site of the variant complexes presented here extends through an open solventexposed crevice that is more than $20 \AA$ long. Therefore the hypothesis that substrates should enter this site via the region around residue 113 is unconvincing.

The structures presented here provide strategies for the development of novel GST P1-1 inhibitors that might inhibit detoxification of chlorambucil and similar alkylating drugs by the enzyme. Firstly, the lack of structural differences between the variants suggest inhibitors can be designed with potency against all variants. (There is no obvious clinical need to develop variant-specific inhibitors). Nevertheless, the different reactivities of the variants towards model co-substrates reported here suggests that any new compound may well display varying levels of inhibition towards variants of the enzyme. Further work is required to understand this behaviour at the molecular level. Secondly, novel GST inhibitors could be synthesised in which the alkylating arms of chlorambucil, which react with GSH and crosslink DNA molecules, are replaced by moieties to enhance interactions with the enzyme. The aim would be to discover molecules that are no longer substrates for the enzyme and will not react non-specifically with other molecules such as DNA. Since we show that chlorambucil is a poor inhibitor of the enzyme, and that it makes relatively few contacts with the enzyme, any such efforts would be best directed towards chlorambucil-GSH analogues, since the parent compound forms more extensive interactions with the enzyme. Finally, the structures presented here define key interacting residues in the active site that are utilised in interactions with chlorambucil that could be used to guide drug discovery through structure-based virtual screening.

In summary, we have explored the molecular basis for the differing behaviour of GST P1-1 polymorphisms, which has been linked to both the differing susceptibilities of people towards certain cancers and the variable response of cancer patients to the common anti-cancer drug chlorambucil. The kinetic data show that catalytic differences are highly substrate-dependent and that, for most of the temperature range explored, the variants are equally stable. We present structural views of how chlorambucil is recognised and deactivated by two polymorphic variants of GST P1-1. The crystal structure of the ${ }^{*} \mathrm{C}$ variant is described for the first time and reveals, consistent with the other variants (unpub- lished results), that residue differences do not affect the three-dimensional structure of the enzyme. The crystal structures reveal key interactions and pinpoint residues that are important for the stabilisation of the chlorambucil molecule within the enzyme. We show that GSH needs to be present in the active site for chlorambucil to bind to the enzyme in a productive complex. The structures provide the basis for designing drugs that might inhibit GST detoxification of chlorambucil and similar clinically available alkylating drugs.

\section{Materials and Methods}

\section{Cloning, expression and purification}

The allelic variants of GST P1-1 were obtained using a Quick Change ${ }^{\mathrm{TM}}$ Site-Direct Mutagenesis Kit (Stratagene). Plasmid pGST1, ${ }^{40}$ was used to generate the singlestranded DNA template used for site-directed mutagenesis as described. ${ }^{19}$ PCR was performed in a DNA thermocycler. The reaction mixture contained $20 \mathrm{ng}$ of DNA template, $125 \mathrm{ng}$ each of forward and reverse primers:

104Val1 5'CTCCGCTGCAAATACGTCTCCCTCATCTACACC3' 104Val2 5'GGTGTAGATGAGGGAGACGTATTTGCAGCGAG-3' 113Val1 5'-CACCAACTATGAGGTGGGCAAGGATGAC-3' 113Val2 5'GTCATCCTTGCCCACCTCATAGTTGGTC3' 104/113Val1 5'CTGCAAATACGTCTCCCTCATCTACACCAACTAGAGGTGGGCAAGGATG3'

104/113Val2 5'CATCCTTGCCCACCTCATAGTTGGTGTAGATGAGGGAGACGTATTTGCA-3'

$10 \times$ PCR buffer, $0.8 \mathrm{nM}$ each dATP, dCTP, dGTP and dTTP. Pfu Turbo ${ }^{\text {TM }}$ polymerase (2.5 units) was added and the mixture was overlaid with distilled water. After one cycle of denaturing $\left(95^{\circ} \mathrm{C}\right.$ for $\left.30 \mathrm{~s}\right), 16$ cycles of denaturing $\left(95^{\circ} \mathrm{C}\right.$ for $\left.30 \mathrm{~s}\right)$, annealing $\left(55^{\circ} \mathrm{C}\right.$ for $\left.1 \mathrm{~min}\right)$ and extension $\left(68^{\circ} \mathrm{C}\right.$ for $5 \mathrm{~min}$ ) were performed. The mixture was used to transform super-competent XL-BLUE Escherichia coli cells ${ }^{41}$ that were inoculated in Luria broth. Plasmid DNA was extracted using Nucleospin Plasmid (Macherey-Nagel GmbH \& Co., Germany) and newly transformed in competent TOP10 E. coli cells. These cells were grown in Luria-Bertani medium containing $100 \mu \mathrm{g}$ $\mathrm{mL}^{-1}$ ampicillin and $50 \mu \mathrm{g} \mathrm{mL}^{-1}$ streptomycin. The synthesis of enzymes (wt, I104V, A113V and I104V/A113V) was induced by addition of $0.5 \mathrm{mM}$ isopropyl- $\beta$-D-thiogalactopyranoside (IPTG) when the absorbance at $600 \mathrm{~nm}$ was 0.5 . At $18 \mathrm{~h}$ after induction the cells were harvested by centrifugation and disrupted by ultrasonication. All the enzymes were purified by affinity chromatography on immobilised $\mathrm{GSH}^{42}$ with a similar yield. After affinity purification, the enzymes were homogeneous as observed by SDS-PAGE (data not shown). The protein concentration was determined by the Lowry method. ${ }^{43}$

\section{Kinetic studies}

The enzymatic-specific activities (Table 1) were determined spectrophotometrically at $25{ }^{\circ} \mathrm{C}$ with selected cosubstrates (CDNB, EA, NBD-Cl) in a double beam Cary 4000 spectrophotometer equipped with a thermostatically controlled cuvette compartment. Apparent kinetic parameters $k_{\text {cat }}, K_{\mathrm{m}}{ }^{\text {cosub }}$ and $k_{\text {cat }} / K_{\mathrm{m}}{ }^{\text {cosub }}$ (Table 2$)$, for different cosubstrates were determined at a fixed concentration of GSH 
and with various concentrations of co-substrate, by fitting the data to the Michaelis-Menten equation using non-linear regression analysis with the GraphPad Prism computer programs (GraphPad Software, San Diego, CA). Briefly, the set of experimental conditions was: (1) 0.05-0.5 mM EA in the presence of $1 \mathrm{mM} \mathrm{GSH}$ in $0.1 \mathrm{M}$ phosphate buffer at $\mathrm{pH}$ 6.5 . The apparent $K_{\mathrm{m}}{ }^{\mathrm{GSH}}$ was obtained at a fixed concentration of EA $(0.5 \mathrm{mM})$ and various concentrations of GSH (0.04-1 mM). The reaction was monitored by following the increase of absorbance at $270 \mathrm{~nm}$ of the EA-GS conjugate $\left(\varepsilon=5700 \mathrm{M}^{-1} \mathrm{~cm}^{-1}\right) ;^{44}$ (2) $0.0025-0.5 \mathrm{mM}$ NBD-Cl in the presence of $0.5 \mathrm{mM} \mathrm{GSH}$ in $0.1 \mathrm{M}$ sodium acetate at $\mathrm{pH}$ 5.0. The reaction was monitored at $419 \mathrm{~nm}(\varepsilon=14,500$ $\left.\mathrm{M}^{-1} \mathrm{~cm}^{-1}\right){ }^{45}$ The apparent $K_{\mathrm{m}}{ }^{\mathrm{GSH}}$ was calculated under the same conditions at a fixed concentration of NBD-Cl (0.2 $\mathrm{mM})$ and various concentrations of GSH $(0.002-0.5 \mathrm{mM}) .3$, $0.1-2 \mathrm{mM}$ CDNB in the presence of $1 \mathrm{mM} \mathrm{GSH}$ in $0.1 \mathrm{mM}$ phosphate buffer at $\mathrm{pH}$ 6.5. The reaction was monitored at $340 \mathrm{~nm}\left(\varepsilon=9600 \mathrm{M}^{-1} \mathrm{~cm}^{-1}\right)$. ${ }^{44}$ The apparent $K_{\mathrm{m}}{ }^{\mathrm{GSH}}$ was also determined at a fixed concentration of CDNB $(1 \mathrm{mM})$ and various concentrations of GSH $(0.02-1 \mathrm{mM})$.

\section{Thermal stability}

The GST P1-1 wt and the I104V, A113V and I104V / A113V mutant enzymes were incubated at different temperatures $\left(10-55^{\circ} \mathrm{C}\right)$ for at least $15 \mathrm{~min}$, at a protein concentration of $0.1 \mathrm{mg} \mathrm{ml}^{-1}$ in $0.1 \mathrm{M}$ phosphate buffer $(\mathrm{pH}$ 6.5). At regular time intervals, aliquots were withdrawn from the incubation mixture and assayed for GST activity at $25^{\circ} \mathrm{C}$ in the presence of $1 \mathrm{mM} \mathrm{GSH}$ and $1 \mathrm{mM} \mathrm{CDNB}$ (Fig. 2). In a separate set of experiments, the same enzymes were incubated at $45{ }^{\circ} \mathrm{C}$ for at least $1 \mathrm{~h}$ under the same conditions and GST activity was assayed at regular intervals, as above. Finally, the enzymatic activity was also checked after $24 \mathrm{~h}$ incubation under the conditions described above.

\section{Inhibition of GST P1-1 wt and the I104V, A113V and I104V/A113V mutant enzymes with chlorambucil}

Various concentrations of chlorambucil dissolved in ethanol were added to a potassium phosphate buffer solution (100 mM, pH 6.5) containing 44 nM GST P1-1 and $1 \mathrm{mM}$ GSH to achieve the final concentrations of 0.5 $500 \mu \mathrm{M}$. The catalytic activity of wt and mutants was assayed spectrophotometrically, upon the addition of the CDNB substrate (final concentration $1 \mathrm{mM}$ ), and plotted against the range of inhibitor concentrations. The activity was determined by fitting the sigmoidal dose-response function using Prism (GraphPad) (Fig. 3).

\section{Expression and purification for crystallisation}

Chlorambucil and GSH were obtained from SigmaAldrich. The wt (*A variant) human pi class GST P1-1 was expressed and purified as described. ${ }^{40}$ Expression and purification of the ${ }^{*} \mathrm{C}$ variant was done as follows: $E$. coli containing the GSTP* $\mathrm{C}$ construct were cultured in LuriaBertani medium containing $100 \mu \mathrm{g} / \mathrm{ml}$ ampicillin and $50 \mu \mathrm{g} / \mathrm{ml}$ streptomycin sulfate. When the $A_{600}$ reached 0.6 expression was induced with $2 \mathrm{mM} \mathrm{IPTG}$ for $4 \mathrm{~h}$ at $37^{\circ} \mathrm{C}$. The cells were harvested by centrifugation for $20 \mathrm{~min}$ at $6000 \mathrm{~g}$ and pellets were resuspended in $50 \mathrm{mM}$ Tris $-\mathrm{HCl}$ (pH 8.0), $100 \mathrm{mM} \mathrm{NaCl}, 1 \mathrm{mM}$ EDTA and $1 \mathrm{mM}$ PMSF. The cells were lysed using an EmulsiFlex-C5 cell crusher and debris was removed by centrifugation at $30,000 \mathrm{~g}$ for 30 min. The supernatant was filtered through a $0.4 \mu \mathrm{m}$ pore size Sartorius filter and loaded onto a $5 \mathrm{ml}$ GSTrap-Hp (GE Healthcare) column. GSTP*C was eluted using a $\mathrm{pH}$ gradient against a solution containing $25 \mathrm{mM} \mathrm{NaCO}$ (pH 10.5), $500 \mathrm{mM} \mathrm{NaCl}$ and $1 \mathrm{mM}$ DTT. Fractions containing $\mathrm{GST}^{*} \mathrm{C}$ were pooled and dialysed overnight against $10 \mathrm{mM} \mathrm{K}_{2} \mathrm{PO}_{4}$ (pH 6.5), $0.1 \mathrm{mM}$ EDTA and $0.1 \mathrm{mM}$ DTT. GSTP*C was concentrated to $7 \mathrm{mg} / \mathrm{ml}$ using an Amicon Ultra-4 filter (10,000 Da cutoff) for crystallisation. Crystallisation was performed by the hanging-drop, vapour-diffusion method. ${ }^{17}$

\section{Structure determination of the chlorambucil * $A$ complex}

Briefly, a $2 \mu \mathrm{l}$ drop of an $8 \mathrm{mg} / \mathrm{ml}$ protein solution in $10 \mathrm{mM}$ phosphate buffer (pH 7.0), $1 \mathrm{mM}$ EDTA and $2 \mathrm{mM}$ mercaptoethanol was mixed with an equal volume of reservoir solution $(25 \%(\mathrm{w} / \mathrm{v})$ ammonium sulfate, $60 \mathrm{mM}$ DTT, 100 mM Mes buffer (pH 5.4) and 10\% (v/v) glycerol). The trials were carried out at a constant temperature of $4{ }^{\circ} \mathrm{C}$. The drops were allowed to equilibrate for one day before they were streak-seeded with a cat's whisker from drops containing crystals grown under similar conditions. Solid chlorambucil was streaked into the drop using a cat's whisker. Crystals appeared in the shape of plates after one week and grew to maximal dimensions of $0.1 \mathrm{~mm} \times 0.3 \mathrm{~mm} \times 0.3 \mathrm{~mm}$. The crystals were left undisturbed for nine weeks before data collection. The Xray diffraction data were collected using a MARResearch area detector with $\mathrm{CuK}_{\alpha} \mathrm{X}$-rays generated by a Rigaku RU-200 rotating anode X-ray generator. The data were collected at $100 \mathrm{~K}$ using an Oxford Cryosystems Cryostream Cooler. Before flash-freezing, the crystal was transferred to artificial mother liquor containing $25 \%$ (v/ v) glycerol. The diffraction data were processed and analysed using programs in the HKL ${ }^{46}$ and CCP4 ${ }^{47}$ suites. Refinement began with the model of the GSH complex in the C2 group ${ }^{30}$ (PDB ID 5GSS) which had GSH and water molecules removed. Rigid body refinement in XPLOR was used to compensate for any possible changes in crystal packing. ${ }^{48}$ As the asymmetric unit of the crystal contained two GST monomers, non-crystallographic symmetry restraints were used throughout the initial rounds of refinement with the exception of some residues involved in crystal contacts. The starting model gave an $R_{\text {cryst }}$ of $33.2 \%$ $\left(R_{\text {free }}=33.9 \%\right)$, which was reduced to $27.6 \%\left(R_{\text {free }}=29.3 \%\right)$ after rigid body refinement. The model was then subjected to two cycles of positional and isotropically restrained individual $B$-factor refinement and inclusion of water molecules $\left(R_{\text {cryst }}=26.5 \%, R_{\text {free }}=29.1 \%\right)$. The $2 F_{\text {chlorambucil }}-$ $F_{\text {native }}$ electron density map calculated from this model was further improved by ten cycles of twofold noncrystallographic averaging using MAMA, ${ }^{49}$ RAVE $^{50}$ and $\mathrm{CCP} 4^{47}$ program suites. The final few rounds of refinement were performed with REFMAC. ${ }^{51}$ The electron density maps allowed unambiguous placement of the chlorambucil molecule in subunit B. (Although there was some electron density in the expected position in subunit A, it was of insufficient quality to build in a chlorambucil ligand). The chlorambucil molecule was built into the map together with buffer molecules and more water molecules. Bond lengths and angles for the chlorambucil were derived from a model built and energy minimised using the programs in the INSIGHT II software suite (Accelrys Inc., San Diego). The model was subjected to a round of positional refinement $\left(R_{\text {cryst }}=24.8 \%, R_{\text {free }}=28.0 \%\right)$. After application of a bulk solvent correction and a few more 
rounds of refinement, the final $R_{\text {cryst }}$ was $17.6 \%\left(R_{\text {free }}=\right.$ $23.3 \%$ ) for all data to $1.9 \AA$ resolution.

\section{Structure determination of the chlorambucil-GSH *A complex}

The protein solution described above was mixed with an equal volume of reservoir buffer $(100 \mathrm{mM}$ Mes buffer (pH 5.5 or 6.0), 22\% (w/v) PEG 8000, $20 \mathrm{mM} \mathrm{CaCl}_{2}, 10 \mathrm{mM}$ DTT, $10 \mathrm{mM}$ GSH). Crystals grew at $22^{\circ} \mathrm{C}$ and reached a suitable size in approximately a week. Two or three crystals from each drop were transferred into $4 \mu \mathrm{l}$ drops of a new reservoir solution containing $100 \mathrm{mM}$ Mes buffer (pH 5.5), 22\% (w/v) PEG 8000, $20 \mathrm{mM} \mathrm{CaCl}_{2}, 10 \mathrm{mM} \mathrm{DTT,}$ $10 \mathrm{mM}$ GSH and a $2 \%(\mathrm{v} / \mathrm{v})$ solution of $2 \mathrm{mM}$ chlorambucil in $100 \%$ ethanol. These were left to soak for two to three weeks. X-ray diffraction data were collected at the Advanced Photon Source (Chicago, IL), beamline 14-BMC using an ADSC Q315 CCD detector. The wavelength was set to $0.90 \AA$. For cryoprotection, the crystals were soaked for $2 \mathrm{~min}$ in the well solution containing $5 \%(\mathrm{v} / \mathrm{v})$ methyl-2,4-pentanediol (MPD), then dipped briefly in well solution containing $10 \%(\mathrm{v} / \mathrm{v}) \mathrm{MPD}$. The crystals were then snap-frozen at $100 \mathrm{~K}$ in the cryostream. Diffraction data were processed and scaled with HKL. ${ }^{46}$ Refinement began with the model of GST P1-1 in complex with GSH $(5 \mathrm{GSS})^{30}$ after GSH and water molecules were removed. Rigid body refinement in $\mathrm{CNS}^{48}$ was used to compensate for any possible changes in crystal packing. The starting model gave an $R_{\text {cryst }}$ of $44.0 \%\left(R_{\text {free }}=48.3 \%\right)$. The model was then refined by a round of simulated annealing using CNS followed by restrained refinement using REFMAC. ${ }^{51}$ Water and Mes molecules were added using COOT, ${ }^{52}$ followed by rounds of restrained refinement in REFMAC $\left(R_{\text {cryst }}=19.5 \% R_{\text {free }}=21.3 \%\right)$ and cycles of positional and isotropically restrained $B$-factor refinement. ${ }^{51}$ After several rounds of refinement, the density for the chlorambucilGSH complex was evident in an $F_{\mathrm{o}}-F_{\mathrm{c}}$ map and was subsequently built into the model. The conjugate was built using Monomer Library Sketcher, ${ }^{47}$ and was subject to a round of regularisation with REFMAC ${ }^{51}$ before its addition to the structure. Inspection of difference maps suggested that the active site of each GST monomer consisted of approximately $80 \%$ conjugate and $20 \%$ unconjugated GSH. A refinement based on these starting occupancies was performed with CNS. ${ }^{48}$ The $B$-factors for surrounding residues after refinement were similar to those of the bound ligands. The $R_{\text {cryst }}$ and $R_{\text {free }}$ for the final model were $17.0 \%$ and $20.0 \%$ respectively for all data to $1.5 \AA$ resolution.

\section{Structure determination of the chlorambucil-GSH ${ }^{*} \mathrm{C}$ complex}

Crystallisation of the ${ }^{*} \mathrm{C}$ variant and introduction of chlorambucil was performed as outlined above for the ${ }^{*} \mathrm{~A}$ variant, except the best crystals grew at $\mathrm{pH} 6.0$ and the soak time was for four days. The X-ray diffraction data were collected using an R-AXIS IV++ area detector with $\mathrm{CuK}_{\alpha} \mathrm{X}$-rays generated by a Rigaku MicroMax-007H rotating anode X-ray generator. For cryoprotection, the crystals were soaked for $2 \mathrm{~min}$ in the well solution containing $5 \%(\mathrm{v} / \mathrm{v}) \mathrm{MPD}$, then dipped briefly in well solution containing $10 \%(\mathrm{v} / \mathrm{v})$ MPD. The crystals were then snapfrozen at $100 \mathrm{~K}$ in the cryostream. Diffraction data were processed with MOSFLM ${ }^{47}$ and scaled with SCALA. ${ }^{47}$ The diffraction data were consistent with the crystals belonging to a new space group, necessitating structure determination by molecular replacement. The calculations were performed with PHASER, ${ }^{53}$ using a dimer of the *A enzyme crystal structure as the search model. Two dimers were located in the asymmetric unit of the new unit cell. The model was then refined by rounds of restrained refinement in REFMAC ${ }^{51}$ (initial $R_{\text {cryst }}$ and $R_{\text {free }}$ were $24.0 \%$ and $28.7 \%$, respectively) and model building in COOT. ${ }^{52}$ After several rounds of refinement, the density for the chlorambucil-GSH complex was evident in an $F_{\mathrm{o}}-F_{\mathrm{c}}$ map and was subsequently built into the model. The conjugate was built using Monomer Library Sketcher, ${ }^{47}$ and was subject to a round of regularisation with REFMAC ${ }^{51}$ before its addition to the structure. The $R_{\text {cryst }}$ and $R_{\text {free }}$ for the final model were $16.6 \%$ and $22.2 \%$, respectively, for all data to $1.9 \AA$ resolution.

A stereochemical analysis of all the refined structures with the program PROCHECK ${ }^{54}$ gave values either similar or better than expected for structures refined at similar resolution.

\section{Protein Data Bank accession numbers}

The models have been deposited in the Protein Data Bank $\uparrow$ under the filenames 3CSJ (chlorambucil complex, *A variant) and $3 \mathrm{CSH}$ (chlorambucil-GSH complex, ${ }^{*} \mathrm{~A}$ variant) and 3CSI (chlorambucil-GSH complex, ${ }^{*} \mathrm{C}$ variant).

\section{Acknowledgements}

We thank Julian Adams, Mike Gorman and Guido Hansen for advice and encouragement. We thank Harry Tong and other BioCARS staff for their help at the Advanced Photon Source. This work was supported by the Australian Synchrotron Research Program, which is funded by the Commonwealth of Australia under the Major National Research Facilities Program. Use of the Advanced Photon Source was supported by the U.S. DOE, Basic Energy Sciences, Office of Energy Research. This work was also supported by grants from the Australian Research Council (ARC) and the Australian Cancer Research Foundation to M.W.P., and from MIUR and Genesys SpA to M.L.B. L.J.P. and A.J.O were supported by the National Health and Medical Research Council of Australia (NHMRC) Dora Lush Scholarships and International Centre for Diffraction Data Crystallography Scholarships. L.C.I was supported by a St. Vincent's Institute Foundation award. M.W.P. is an ARC Federation Fellow and NHMRC Honorary Fellow.

\section{References}

1. Sheehan, D., Meade, G., Foley, V. M. \& Dowd, C. A. (2001). Structure, function and evolution of glutathione transferases: implications for classification of non-mammalian members of an ancient enzyme superfamily. Biochem. J. 360, 1-16.

2. Hayes, J. D., Flanagan, J. U. \& Jowsey, I. R. (2005). Glutathione transferases. Annu. Rev. Pharmacol. Toxicol. $45,51-88$.

$\dagger$ †ttp:/ / www.rcsb.org/pdb/ 
3. Wilce, M. C. \& Parker, M. W. (1994). Structure and function of glutathione S-transferases. Biochim. Biophys. Acta, 1205, 1-18.

4. Inoue, T., Ishida, T., Sugio, K., Maehara, Y. \& Sugimachi, K. (1995). Glutathione $\mathrm{S}$ transferase $\mathrm{Pi}$ is a powerful indicator in chemotherapy of human lung squamous-cell carcinoma. Respiration, 62, 223-227.

5. Sato, K. (1989). Glutathione transferases as markers of preneoplasia and neoplasia. Adv. Cancer Res. 52, 205-255.

6. Ruiz-Gomez, M. J., Souviron, A., Martinez-Morillo, M. \& Gil, L. (2000). P-glycoprotein, glutathione and glutathione S-transferase increase in a colon carcinoma cell line by colchicine. J. Physiol. Biochem. 56, 307-312.

7. Green, J. A., Robertson, L. J. \& Clark, A. H. (1993). Glutathione S-transferase expression in benign and malignant ovarian tumours. Br. J. Cancer, 68, 235-239.

8. Katagiri, A., Tomita, Y., Nishiyama, T., Kimura, M. \& Sato, S. (1993). Immunohistochemical detection of Pglycoprotein and GSTP1-1 in testis cancer. Br. J. Cancer, 68, 125-129.

9. Singh, S. V., Xu, B. H., Gupta, V., Emerson, E. O., Zaren, H. A. \& Jani, J. P. (1995). Characterization of a human bladder cancer cell line selected for resistance to BMY 25067, a novel analogue of mitomycin C. Cancer Lett. 95, 49-56.

10. Zhang, L., Xiao, Y. \& Priddy, R. (1994). Increase in placental glutathione S-transferase in human oral epithelial dysplastic lesions and squamous cell carcinomas. J. Oral Pathol. Med. 23, 75-79.

11. Grignon, D. J., Abdel-Malak, M., Mertens, W. C., Sakr, W. A. \& Shepherd, R. R. (1994). Glutathione Stransferase expression in renal cell carcinoma: a new marker of differentiation. Mod. Pathol. 7, 186-189.

12. Brabender, J., Lord, R. V., Wickramasinghe, K., Metzger, R., Schneider, P. M., Park, J. M. et al. (2002). Glutathione S-transferase-pi expression is downregulated in patients with Barrett's esophagus and esophageal adenocarcinoma. J. Gastrointest. Surg. 6, 359-367.

13. Okuyama, T., Maehara, Y., Endo, K., Baba, H., Adachi, Y., Kuwano, M. \& Sugimachi, K. (1994). Expression of glutathione S-transferase-pi and sensitivity of human gastric cancer cells to cisplatin. Cancer, 74, 1230-1236.

14. Cairns, P., Esteller, M., Herman, J. G., Schoenberg, M., Jeronimo, C., Sanchez-Cespedes, M. et al. (2001). Molecular detection of prostate cancer in urine by GSTP1 hypermethylation. Clin. Cancer Res. 7, 2727-2730.

15. Ricci, G., Lo Bello, M., Caccurri, A. M., Pastore, A., Nuccetelli, M., Parker, M. W. \& Federici, G. (1995) Site-directed mutagenesis of human glutathione transferase P1-1. Mutation of Cys-47 induces a positive cooperatively in glutathione transferase P1-1. J. Biol. Chem. 270, 1243-1248.

16. Lo Bello, M., Battistoni, A., Mazzetti, A. P., Board, P. G., Muramatsu, M., Federici, G. \& Ricci, G. (1995). Site-directed mutagenesis of human glutathione transferase P1-1. Spectral, kinetic, and structural properties of Cys-47 and Lys-54 mutants. J. Biol. Chem. 270, 1249-1253.

17. Cesareo, E., Parker, L. J., Pedersen, J. Z., Nuccetelli, M., Mazzetti, A. P., Pastore, A. et al. (2005). Nitrosylation of human glutathione transferase P1-1 with dinitrosyl diglutathionyl iron complex in vitro and in vivo. J. Biol. Chem. 280, 42172-42180.

18. Caccuri, A. M., Antonini, G., Ascenzi, P., Nicotra, M., Nuccetelli, M., Mazzetti, A. P. et al. (1999). Temperature adaptation of glutathione S-transferase P1-1. A case for homotropic regulation of substrate binding. J. Biol. Chem. 274, 19276-19280.
19. Lo Bello, M., Oakley, A. J., Battistoni, A., Mazzetti, A. P., Nuccetelli, M., Mazzarese, G. et al. (1997). Multifunctional role of Tyr 108 in the catalytic mechanism of human glutathione transferase P1-1. Crystallographic and kinetic studies on the Y108F mutant enzyme. Biochemistry, 36, 6207-6217.

20. Ricci, G., Caccuri, A. M., Lo Bello, M., Rosato, N., Mei, G., Nicotra, M. et al. (1996). Structural flexibility modulates the activity of human glutathione transferase P1-1. Role of helix 2 flexibility in the catalytic mechanism. J. Biol. Chem. 271, 16187-16192.

21. Caccuri, A. M., Ascenzi, P., Antonini, G., Parker, M. W., Oakley, A. J., Chiessi, E. et al. (1996). Structural flexibility modulates the activity of human glutathione transferase P1-1. Influence of a poor co-substrate on dynamics and kinetics of human glutathione transferase. J. Biol. Chem. 271, 16193-16198.

22. Ahmad, H., Wilson, D. E., Fritz, R. R., Singh, S. V., Medh, R. D., Nagle, G. T. et al. (1990). Primary and secondary structural analyses of glutathione S-transferase pi from human placenta. Arch. Biochem. Biophys. 278, 398-408.

23. Ali-Osman, F., Akande, O., Antoun, G., Mao, J. X. \& Buolamwini, J. (1997). Molecular cloning, characterization, and expression in Escherichia coli of fulllength cDNAs of three human glutathione S-transferase $\mathrm{Pi}$ gene variants. Evidence for differential catalytic activity of the encoded proteins. J. Biol. Chem. 272, 10004-10012.

24. Allan, J. M., Wild, C. P., Rollinson, S., Willett, E. V., Moorman, A. V., Dovey, G. J., Roddam, P. L., Roman, E., Cartwright, R. A. \& Morgan, G. J. (2001). Polymorphism in glutathione S-transferase P1 is associated with susceptibility to chemotherapy-induced leukemia. Proc. Natl Acad. Sci. USA, 98, 1157-11592.

25. Tew, K. D., Dutta, S. \& Schultz, M. (1997). Inhibitors of glutathione S-transferases as therapeutic agents. Adv. Drug Deliv. Rev. 26, 91-104.

26. Foon, K. A., Rai, K. R. \& Gale, R. P. (1990). Chronic lymphocytic leukemia: new insights into biology and therapy. Ann. Intern. Med. 113, 525-539.

27. Ciaccio, P. J., Tew, K. D. \& LaCreta, F. P. (1990). The spontaneous and glutathione S-transferase-mediated reaction of chlorambucil with glutathione. Cancer Commun. 2, 279-285.

28. Pandya, U., Srivastava, S. K., Singhal, S. S., Pal, A., Awasthi, S., Zimniak, P. et al. (2000). Activity of allelic variants of Pi class human glutathione S-transferase toward chlorambucil. Biochem. Biophys. Res. Commun. 278, 258-262.

29. Horton, J. K., Roy, G., Piper, J. T., van Houten, B., Awasthi, Y. C., Mitra, S. et al. (1999). Characterization of a chlorambucil-resistant human ovarian carcinoma cell line overexpressing glutathione S-transferase $\mathrm{m}$. Biochem. Pharmacol. 58, 693-702.

30. Oakley, A. J., Lo Bello, M., Battistoni, A., Ricci, G., Rossjohn, J., Villar, H. O. \& Parker, M. W. (1997). The structures of human glutathione transferase P1-1 in complex with glutathione and various inhibitors at high resolution. J. Mol. Biol. 274, 84-100.

31. Hathout, Y., Ellis, T., Fabris, D. \& Fenselau, C. (1996). Cross-linking of human placenta pi class glutathione S-transferase dimer by chlorambucil. Chem. Res. Toxicol. 9, 1044-1049.

32. Reinemer, P., Dirr, H. W., Ladenstein, R., Huber, R., Lo Bello, M., Federici, G. \& Parker, M. W. (1992). Threedimensional structure of class pi glutathione S-transferase from human placenta in complex with S-hexylglutathione at $2.8 \AA$ resolution. J. Mol. Biol. 227, 214-226. 
33. Oakley, A. J., Rossjohn, J., Lo Bello, M., Caccuri, A. M., Federici, G. \& Parker, M. W. (1997). The threedimensional structure of the human $\mathrm{Pi}$ class glutathione transferase P1-1 in complex with the inhibitor ethacrynic acid and its glutathione conjugate. Biochemistry, 36, 576-585.

34. Zimniak, P., Nanduri, B., Pikula, S., BandorowiczPikula, J., Singhal, S. S., Srivastava, S. K. et al. (1994). Naturally occurring human glutathione S-transferase GSTP1-1 isoforms with isoleucine and valine in position 104 differ in enzymic properties. Eur. J. Biochem. 224, 893-899.

35. Johansson, A. S., Stenberg, G., Widersten, M. \& Mannervik, B. (1998). Structure-activity relationships and thermal stability of human glutathione transferase P1-1 governed by the H-site residue 105. J. Mol. Biol. 278, 687-698.

36. Oakley, A. J., Lo Bello, M., Mazzetti, A. P., Federici, G. \& Parker, M. W. (1997). The glutathione conjugate of ethacrynic acid can bind to human pi class glutathione transferase P1-1 in two different modes. FEBS Lett. 419, $32-36$.

37. Ji, X., Tordova, M., O'Donnell, R., Parsons, J. F., Hayden, J. B., Gilliland, G. L. \& Zimniak, P. (1997). Structure and function of the xenobiotic substratebinding site and location of a potential non-substratebinding site in a class pi glutathione S-transferase. Biochemistry, 36, 9690-9702.

38. Ji, X., Blaszczyk, J., Xiao, B., O’Donnell, R., Hu, X., Herzog, C. et al. (1999). Structure and function of residue 104 and water molecules in the xenobiotic substrate-binding site in human glutathione S-transferase P1-1. Biochemistry, 38, 10231-10238.

39. Hu, X., Xia, H., Srivastava, S. K., Herzog, C., Awasthi, Y. C., Ji, X. et al. (1997). Activity of four allelic forms of glutathione S-transferase hGSTP1-1 for diol epoxides of polycyclic aromatic hydrocarbons. Biochem. Biophys. Res. Commun. 238, 397-402.

40. Battistoni, A., Mazzetti, A. P., Petruzzelli, R., Muramatsu, M., Federici, G., Ricci, G. \& Lo Bello, M. (1995). Cytoplasmic and periplasmic production of human placental glutathione transferase in Escherichia coli. Protein Expr. Purif. 6, 579-587.

41. Kramer, B., Kramer, W. \& Fritz, M. J. (1984). Different base/base mismatches are corrected with different efficiencies by the methyl-directed DNA mismatchrepair system of E. coli. Cell, 38, 879-887.
42. Simon, P. C. \& Vander Jagt, D. L. (1977). Purification of glutathione S-transferase from human liver by affinity chromatography. Anal. Biochem. 82, 334-341.

43. Lowry, O. H., Rosebrough, N. J., Farr, A. L. \& Randall, R. J. (1951). Protein measurement with the Folin Phenol reagent. J. Biol. Chem. 193, 265-275.

44. Habig, W. H., Pabst, M. T. \& Jakoby, W. B. (1974). Glutathione S-transferases. The first enzymatic step in mercapturic acid formation. J. Biol. Chem. 249, 7130-7139.

45. Ricci, G., Caccuri, A. M., Lo Bello, M., Pastore, A., Piemonte, F. \& Federici, G. (1994). Colorimetric and fluorometric assays of glutathione transferase based on 7-chloro-4-nitrobenzo-2-oxa-1,3-diazole. Anal. Biochem. 218, 463-465.

46. Otwinowski, Z. \& Minor, W. (1997). Processing of X-ray diffraction data collected in the oscillation mode. Methods Enzymol. 276, 307-326.

47. Collaborative Computational Project Number 4 (1994). The CCP4 suite: programs for protein crystallography. Acta Crystallogr. D, 50, 760-763.

48. Brünger, A. T., Adams, P. D., Clore, G. M., Delano, W. L., Gros, P., Grosse-Kunstleve, R. W. et al. (1998). Crystallography and NMR systems: a new software suite for macromolecular structure determination. Acta Crystallogr. D, 54, 905-921.

49. Kleywegt, G. J. \& Jones, T. A. (1999). Software for handling macromolecular envelopes. Acta Crystallogr. $D, 55,941-944$.

50. Kleywegt, G. J. \& Jones, T. A. (1996). xdlMAPMAN and xdIDATAMAN - programs for reformatting, analysis and manipulation of biomacromolecular electron-density maps and reflection data sets. Acta Crystallogr. D, 52, 826-828.

51. Murshudov, G. N., Vagin, A. A. \& Dodson, E. J. (1997). Refinement of macromolecular structures by the maximum-likelihood method. Acta Crystallogr. D, 53, 240-255.

52. Emsley, P. \& Cowtan, K. (2004). Coot: model-building tools for molecular graphics. Acta Crystallogr. D, 60, 2126-2132.

53. Storoni, L. C., McCoy, A. J. \& Read, R. J. (2004). Likelihood-enhanced fast rotation functions. Acta Crystallogr. D, 60, 432-438.

54. Laskowski, R. A., MacArthur, M. W., Moss, D. S. \& Thornton, J. M. (1993). PROCHECK: a program to check the stereochemical quality of protein structures. J. Appl. Crystallogr. 26, 283-291. 